\section{Metais presentes no chorume coletado no aterro sanitário de Ribeirão Preto, São Paulo, Brasil, e sua relevância para saúde pública}

\author{
Metals in landfill leachate in Ribeirão Preto, \\ São Paulo State, Brazil, and its relevance for \\ public health
}

\author{
${ }^{1}$ Escola de Enfermagem de \\ Ribeirão Preto, Universidade \\ de São Paulo, Ribeirão Preto, \\ Brasil. \\ 2 Faculdade de Medicina de \\ Ribeirão Preto, Universidade \\ de São Paulo, Ribeirão Preto \\ Brasil. \\ Correspondência \\ S. I. Segura-Muñoz \\ Escola de Enfermagem de \\ Ribeirão Preto, Universidade \\ de São Paulo. \\ Rua Rio Xingú 594, Ribeirão \\ Preto, SP 14060-240, Brasil. \\ susis@eerp.usp.br
}

\section{Abstract}

This study analyzed the levels of cadmium, lead, copper, chromium, manganese, mercury, and zinc in leachate from the Ribeirão Preto landfill site in São Paulo State, Brazil. Samples were taken from runoff tanks in Module I (operating from 1989 to 2000) and Module II (operating since November 2000). Metal levels were measured by atomic absorption spectrophotometry at the University of São Paulo in Ribeirão Preto (University Hospital). Results were compared to the maximum limits for metal concentration in liquid effluents set by Ruling 357/2005 of the National Environmental Council (CONAMA). The study also investigated whether there was any attenuation in metal concentrations in the leachate, considering differences in the life spans of the various Ribeirão Preto landfill site modules. Metal levels in the samples were within the maximum limits for cadmium, chromium, copper, mercury, and manganese, but lead and zinc were above the limits set by the above-mentioned ruling.

Heavy Metals; Sanitary Landfills; Garbage
Marina Smidt Celere 1 Aline da Silva Oliveira 1 Tânia Maria Beltramini Trevilato 2 Susana Inés Segura-Muñoz ${ }^{1}$

\section{Introdução}

A Organização Mundial da Saúde (OMS) define saneamento como o controle de fatores que atuam sobre o meio ambiente e que exercem, ou podem exercer, efeitos prejudiciais ao bem-estar físico, mental ou social do homem. Dentro dessa definição, encaixa-se o conceito de limpeza urbana, que engloba, além de outros serviços, a coleta, o tratamento e a destinação final do lixo ou resíduos sólidos.

Atualmente, uma das grandes preocupações ambientais está relacionada aos resíduos sólidos gerados pela sociedade moderna e consumista. Com a intensificação do processo industrial, aliada ao crescimento da população e à conseqüente demanda por bens de consumo, o homem tem produzido quantidades significativas de resíduos sólidos, que acabam sendo constituídos de uma mistura muito complexa e de natureza diversa, cujos principais constituintes são: material orgânico, papel, vidro, plástico e metais 1 .

Em 2000, o lixo produzido diariamente no Brasil chegava a 125.281 toneladas. Considerando por município, $63,6 \%$ utilizavam lixões, $13,8 \%$, aterros sanitários, $18,4 \%$, aterros controlados, e $5 \%$ não informaram para onde iam seus resíduos. Em 1989, a Pesquisa Nacional de Saneamento Básico (PNSB) mostrava que o percentual de municípios que depositam seus resíduos de forma adequada era de apenas $10,7 \% 2$. 
As áreas de despejo e de disposição dos resíduos sólidos (lixões, aterros controlados e aterros sanitários) não podem ser consideradas como o ponto final para muitas das substâncias contidas nos resíduos ali dispostos ou produzidas pelo lixo urbano, pois, quando a água - principalmente das chuvas - percola através desses resíduos, várias dessas substâncias orgânicas e inorgânicas são carreadas pelo chorume, líquido escuro que contém altas concentrações de compostos orgânicos e inorgânicos. A composição físico-química do chorume é extremamente variável, dependendo de fatores que vão desde as condições pluviométricas locais até tempo de disposição e características do próprio lixo. Esse líquido pode conter altas concentrações de metais pesados, sólidos suspensos e compostos orgânicos originados da degradação de substâncias que são metabolizadas, como carboidratos, proteínas e gorduras. Por apresentar substâncias altamente solúveis, pode escorrer e alcançar as coleções hídricas superficiais ou até mesmo infiltrar-se no solo e atingir as águas subterrâneas, comprometendo sua qualidade e potenciais usos 3,4 .

O estudo dos metais pesados no chorume e em outras matrizes ambientais vem sendo considerado prioritário nos programas de promoção da saúde em escala mundial 5 , pois todas as formas de vida podem ser afetadas direta ou indiretamente pela presença de metais pesados. Muitos metais são essenciais para o crescimento de todos os tipos de organismos, desde bactérias até o ser humano, mas eles são requeridos em baixas concentrações, porque, quando em altas concentrações, podem danificar os sistemas biológicos por apresentarem características bioacumulativas no organismo 6 .

No Brasil, o chorume coletado nos tanques de captação dos aterros sanitários é re-circulado e/ou transportado para estações de tratamento de esgoto, onde é submetido à degradação microbiológica 7. Posteriormente, é lançado, juntamente com o esgoto tratado, em águas superficiais. Sendo desconhecidas as identidades dos compostos presentes no chorume, não é possível prever a efetividade desse tratamento de forma permanente.

Nesse contexto, considera-se importante o monitoramento constante da qualidade do chorume e também da qualidade das águas subterrâneas, que em muitas cidades brasileiras são fonte de abastecimento para a população.

Em Ribeirão Preto, São Paulo, toda a água que abastece a cidade vem de um imenso reservatório de águas subterrâneas chamado Aqüífero Guarani. Esse reservatório estende-se por vários Estados, além de São Paulo. Ocupa uma área de
1,2 milhão de $\mathrm{km}^{2}$, dos quais $70 \%$ encontram-se no Brasil. A água está embebida em uma camada de arenito, que funciona como uma esponja, absorvendo as águas da chuva que se infiltram, o que abastece continuamente o aqüífero na área de afloramento. Vale ressaltar que o aterro sanitário de Ribeirão Preto não está localizado na área de recarga do Aqüífero Guarani, no entanto, considerando sua vulnerabilidade, deve ser especialmente protegido a fim de evitar a contaminação de suas águas por infiltração de metais pesados 8 .

Este estudo teve como objetivo determinar os níveis de Cádmio (Cd), Chumbo (Pb), Cobre $(\mathrm{Cu})$, Cromo $(\mathrm{Cr})$, Manganês (Mn), Mercúrio (Hg) e Zinco (Zn) no chorume coletado nos dois tanques de captação do módulo I e II do aterro sanitário de Ribeirão Preto. As concentrações de metais presentes no líquido coletado no aterro sanitário de Ribeirão Preto foram analisadas segundo a Resolução no. 357/2005 do Conselho Nacional do Meio Ambiente (CONAMA) 9, que define os valores máximos permitidos para concentração de metais em efluentes líquidos. Outro objetivo foi avaliar se existe atenuação na concentração de metais do módulo I para o II do aterro sanitário de Ribeirão Preto, considerando a diferença no tempo de vida dos módulos. Além disso, buscou-se, com este estudo, analisar se a descarga de chorume na Estação de Tratamento de Esgoto por Lodos Ativados do Município de Ribeirão Preto afeta esse sistema de tratamento, em virtude da presença de metais caracterizados como bio-acumulativos e com alto potencial de contaminação ambiental, que se estende desde o início da operação de um aterro sanitário até décadas após seu fechamento.

\section{Material e métodos}

O presente trabalho foi desenvolvido no aterro sanitário de Ribeirão Preto, no qual são depositadas 480 toneladas por dia de resíduos urbanos 5 . O aterro começou suas atividades no ano de 1989, e o primeiro módulo de captação do chorume operou até outubro do ano de 2000; atualmente, encontra-se em funcionamento o módulo II, que está em operação desde novembro do ano de 2000. No total, foram coletadas, em duplicata, 60 amostras de chorume: 30 amostras no tanque de captação do módulo I e 30 no tanque de captação do módulo II, nos meses de julho e agosto de 2004. A Figura 1 mostra a localização do aterro sanitário de Ribeirão Preto e dos tanques de captação do chorume.

Todos os materiais utilizados para coleta e acondicionamento das amostras eram de polie- 
Localização dos tanques de captação do chorume do aterro sanitário de Ribeirão Preto, São Paulo, Brasil.
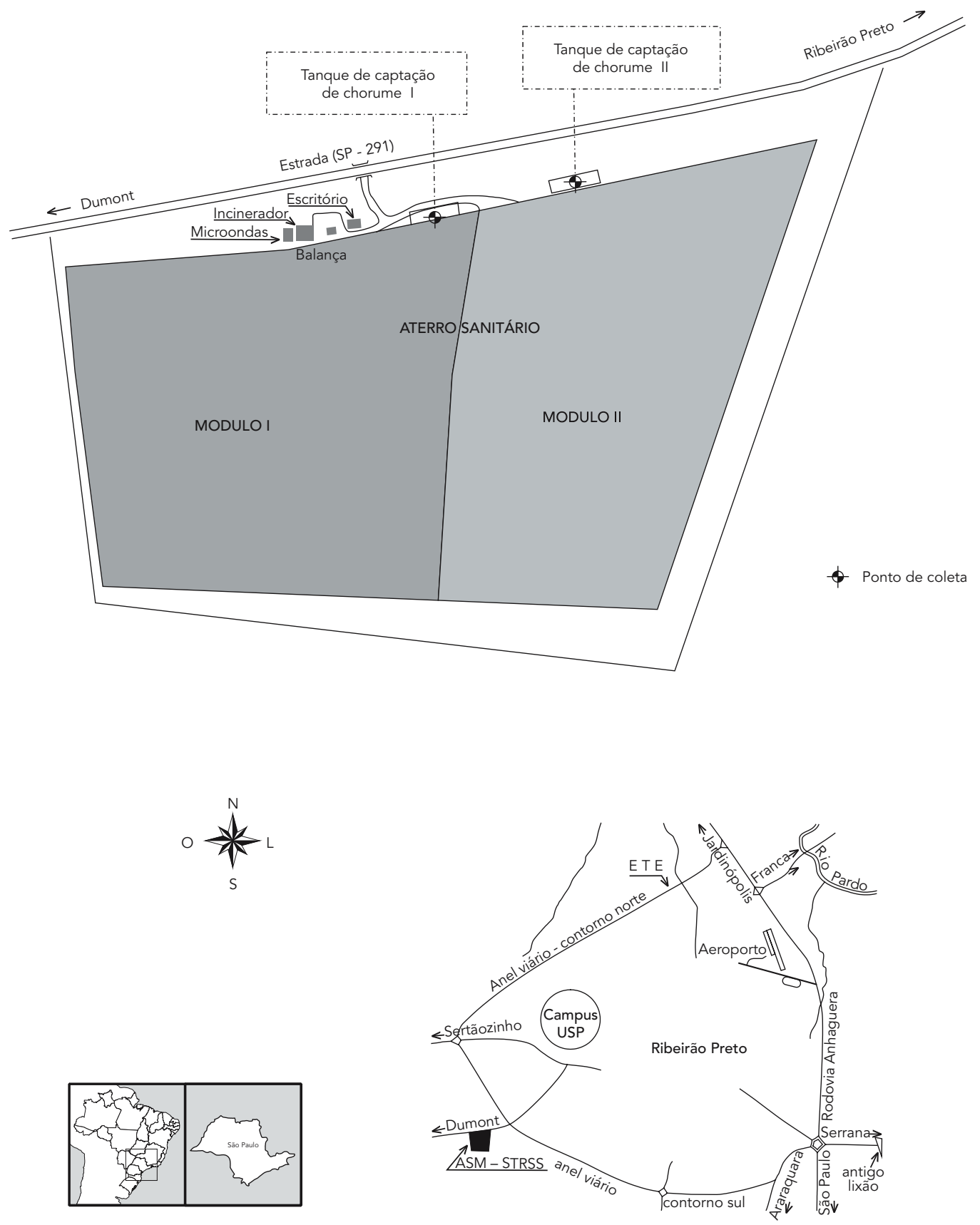

$\begin{array}{llll}0 & 75 & 150 & 300\end{array}$ 
tileno, previamente submergidos em solução de $\mathrm{HNO}_{3}(30 \%$ v/v - Suprapur, E. Merck, Darmstad, Alemanha) por 24 horas, para eliminação de metais interferentes ${ }^{10}$. Posteriormente, foram enxaguados com água Milli-Q no Setor de Metais do Laboratório de Pediatria do Hospital das Clínicas da Faculdade de Medicina de Ribeirão Preto, Universidade de São Paulo (HCFMRP/USP). Para a coleta de amostras de chorume, foram utilizadas garrafas de polietileno de $300 \mathrm{ml}$, providas de tampa; em seguida, as amostras foram fixadas adicionando-se $\mathrm{HNO}_{3}$ de alta pureza, sendo mantidas a $-18^{\circ} \mathrm{C}$ até o momento de preparação. Todos os equipamentos para acondicionamento do material coletado foram etiquetados e devidamente identificados.

As amostras de chorume foram digeridas entre 80 e $110^{\circ} \mathrm{C}$, colocando-se $1 \mathrm{ml}$ de cada amostra e $5 \mathrm{ml}$ de $\mathrm{HNO}_{3}(65 \% \mathrm{v} / \mathrm{v}$ - Suprapur, E. Merck, Darmstad, Alemanha) em tubos de vidro Kjeldahl. Após completa digestão, o conteúdo foi transferido para um frasco volumétrico de $25 \mathrm{ml}$ e teve completado o volume; uma vez esfriado, foi filtrado, utilizando-se papel de filtro Whatman 40 11. Para as dosagens de metais, realizou-se o processo de evaporação, com a finalidade de minimizar a concentração de $\mathrm{HNO}_{3}$ nas amostras. Esse processo consistiu na evaporação, em banho de areia, de $10 \mathrm{ml}$ de amostra digerida e na sua reconstituição com $10 \mathrm{ml}$ de água Milli-Q.

As dosagens de $\mathrm{Cr}, \mathrm{Pb}$, $\mathrm{Cd}$ e $\mathrm{Mn}$ nas amostras de chorume foram feitas por Espectrofotometria de Absorção Atômica com Forno de Grafite (EAA-FG-VARIAN-ZEEMAN/modelo 640-Z); a dosagem de $\mathrm{Hg}$ foi realizada por Espectrofotometria de Absorção Atômica com Geração de Hidreto (EAA-GH-VARIAN-ZEEMAN/modelo AA200) e as dosagens de $\mathrm{Zn}$ e $\mathrm{Cu}$ foram realizadas por Espectrofotometria de Absorção Atômica de Chama (EAA-Chama-VARIAN/modelo AA-55). Utilizaram-se padrões certificantes de água não potável (NW 343; NW 344; NW 348; NW 373; NW 378; NW 388) do Quality Control Technologies Pty Ltd. (Queensland, Austrália).

Os limites de detecção dos métodos utilizados para a análise dos metais presentes são 0,0001 mg/L para Cd e Hg; 0,001mg/L para $\mathrm{Pb}, \mathrm{Zn}$ e Mn; 0,002mg/L para Cr e 0,4mg/L para Cu.

Os testes estatísticos foram realizados por meio do Programa Estatístico GraphPad Prism (Version 3.02 for Windows, GraphPad Software, San Diego, Estados Unidos). Os valores obtidos nos diferentes módulos (I e II) de coleta das amostras de chorume foram comparados utilizando-se o teste estatístico Mann- Whitney.

\section{Resultados e discussão}

O chorume é um líquido escuro de composição fisico-química e microbiológica variada. De forma geral, sabe-se que contém compostos orgânicos polares, apolares, além de metais pesados que podem contaminar o meio ambiente, principalmente se resíduos industriais fazem parte do lixo depositado em um aterro sanitário 12 .

Na Tabela 1, são apresentados os valores médios, desvio padrão, mediana, valor mínimo e máximo de cada metal dosado para o módulo I e II do aterro sanitário de Ribeirão Preto. Nessa mesma tabela também são apresentados os valores máximos recomendados pela Resolução $n^{\circ}$. 357/2005 do CONAMA 9, que dispõe sobre a classificação dos corpos de água e diretrizes ambientais para o seu enquadramento, bem como estabelece as condições e padrões de lançamento de efluentes.

Quanto aos metais dosados nas amostras de chorume coletadas nos módulos I e II do aterro sanitário de Ribeirão Preto, os valores médios encontrados para os metais $\mathrm{Cr}, \mathrm{Cd}, \mathrm{Cu}, \mathrm{Mn}$ e Hg encontram-se dentro dos limites máximos estabelecidos pela Resolução no. 357/2005 do CONAMA 9 . No entanto, cabe apontar que, para o Mn, mesmo obtendo valores médios dentro da referida resolução em ambos os módulos, em $8,3 \%$ das amostras analisadas foram detectados valores que superaram o valor máximo permitido; em adição, os valores médios de $\mathrm{Pb}$ e $\mathrm{Zn}$ apresentaram-se acima dos limites especificados.

Ao comparar as concentrações obtidas no módulo I e no módulo II, evidencia-se que os metais $\mathrm{Cd}, \mathrm{Cr}, \mathrm{Cu}, \mathrm{Hg}, \mathrm{Pb}$ e $\mathrm{Zn}$ não apresentam diferenças estatisticamente significantes ( $p$ > 0,05); unicamente o Mn apresentou valores significativamente superiores nas amostras coletadas no módulo I ( $p=0,0003$ ). Segundo Castilhos Jr. 13, a fração da matéria orgânica aparece como fonte principal dos metais $\mathrm{Ni}, \mathrm{Hg}, \mathrm{Cu}, \mathrm{Pb}$ e $\mathrm{Zn}$. Os plásticos aparecem como principal fonte de $\mathrm{Cd}$; o $\mathrm{Pb}$ e o $\mathrm{Cu}$ se manifestam em quantidades importantes nos metais ferrosos e o papel também é uma fonte importante de $\mathrm{Pb}$. Os resultados obtidos no presente estudo sugerem que quantidades importantes de metais ferrosos, papéis e matéria orgânica devem estar sendo depositadas no aterro sanitário de Ribeirão Preto. Considerando-se que, atualmente, os principais usos do Mn são na produção de aço, baterias, palitos de fósforo e porcelanas, o valor desse metal encontrado no presente estudo pode indicar a presença desses materiais nos resíduos sólidos que estão sendo encaminhados para o aterro sanitário de Ribeirão Preto 14 . 
Concentração de metais no chorume coletado nos módulos I e II do aterro sanitário de Ribeirão Preto, São Paulo, Brasil, e respectivos valores máximos permitidos.

\begin{tabular}{|c|c|c|c|c|c|c|c|c|}
\hline \multirow[t]{2}{*}{ Módulo } & \multirow[t]{2}{*}{ Parâmetro } & \multicolumn{7}{|c|}{ Elementos (concentração expressada em mg/L) } \\
\hline & & $\mathrm{Cd}$ & $\mathrm{Cr}$ & $\mathrm{Cu}$ & $\mathrm{Hg}$ & Mn & $\mathrm{Pb}$ & $\mathrm{Zn}$ \\
\hline \multirow[t]{5}{*}{ I } & Média & 0,010 & 0,175 & ND & ND & 0,676 & 2,085 & 8,429 \\
\hline & Desvio-padrão & 0,013 & 0,087 & ND & ND & 0,689 & 1,998 & 7,421 \\
\hline & Mínimo & 0,002 & 0,032 & ND & ND & 0,30 & 0,715 & 1,620 \\
\hline & Máximo & 0,077 & 0,362 & 0,60 & 0,002 & 4,085 & 11,08 & 33,937 \\
\hline & Mediana & 0,007 & 0,173 & ND & ND & 0,485 & 1,566 & 5,222 \\
\hline \multirow[t]{5}{*}{ II } & Média & 0,012 & 0,164 & ND & ND & 0,428 & 2,372 & 9,146 \\
\hline & Desvio-padrão & 0,010 & 0,081 & ND & ND & 0,402 & 1,608 & 7,913 \\
\hline & Mínimo & 0,002 & 0,075 & ND & ND & 0,122 & 0,640 & 1,822 \\
\hline & Máximo & 0,042 & 0,407 & ND & 0,037 & 1,927 & 6,707 & 34,72 \\
\hline & Mediana & 0,010 & 0,143 & ND & ND & 0,298 & 1,721 & 5,898 \\
\hline \multicolumn{2}{|c|}{ Valores máximos permitidos * } & 0,2 & 0,5 & 1,0 & 0,01 & 1,0 & 0,5 & 5,0 \\
\hline
\end{tabular}

ND: valores abaixo do limite de detecção.

* Segundo Resolução no. 357/2005 do CONAMA 9.

No estudo realizado por Kujara et al. 15, foram dosados níveis de metais pesados no chorume não recirculado, coletado no Depósito Municipal de Lixo na zona norte de Porto Alegre, responsável por receber resíduos de origem urbana. Os níveis máximos e mínimos de metais dosados foram: 0,003 a 2,0mg/L para Cd; 0,01 a $0,015 \mathrm{mg} / \mathrm{L}$ para Cu; 0,01 a 0,3mg/L para Cr e 0,07 a 20,5mg/L para Mn. As concentrações reportadas dos metais pesados apresentam-se similares quando comparadas com as detectadas neste trabalho. Vale ressaltar que a concentração de Mn no estudo de Kujara et al. 15 apresentou valores acima do limite máximo permitido pela Resolução $n^{\circ}$. 357/2005 do CONAMA 9, valores que foram ainda superiores aos detectados no presente estudo, no qual unicamente algumas amostras apresentaram valores de Mn que excederam o limite máximo permitido pela referida resolução.

Oliveira \& Jucá 12 reportaram valores máximos e mínimos de: 0,2 a 2,9mg/L para $\mathrm{Cu},<0,01$ a 3,5mg/L para $\mathrm{Cr},<0,01$ a $1,5 \mathrm{mg} / \mathrm{L}$ para $\mathrm{Pb}$ e $<$ 0,01 a 35mg/L para Mn, em amostras de chorume coletadas no Aterro de Resíduos Sólidos da Muribeca, situado na região metropolitana de Recife, Pernambuco. Quando comparados com os resultados da presente pesquisa, verifica-se que o chorume gerado no aterro sanitário de Ribeirão Preto apresenta valores máximos menores para os metais $\mathrm{Cu}$, Cr e Mn e valor máximo maior para o metal $\mathrm{Pb}$. Essa diferença pode ser justificada pelo fato de o aterro sanitário de Ribeirão Preto receber apenas resíduos de origem urbana, enquanto o Aterro de Muribeca recebe resíduos de origem urbana, hospitalar e industrial.

Na Figura 2, são apresentadas as variações na concentração dos metais analisados segundo o dia de coleta nos tanques de captação do chorume dos módulos I e II do aterro sanitário de Ribeirão Preto. O Cu não foi apresentado graficamente, pois apresentou a maioria dos valores abaixo do limite de detecção nas amostras coletadas.

Evidencia-se, na Figura 2, a variabilidade nas concentrações dos metais analisados no período da coleta, tanto no chorume captado no módulo I, quanto no captado no módulo II do aterro sanitário de Ribeirão Preto, independentemente da idade dos módulos e da fase de decomposição dos resíduos sólidos.

Em estudo realizado no ano de 2000 por Segura-Muñoz ${ }^{16}$ no aterro sanitário de Ribeirão Preto, foram dosados metais em amostras do tanque de captação no único módulo existente na época, o módulo I, e verificou-se que as concentrações de $\mathrm{Cd}, \mathrm{Cu}, \mathrm{Mn}, \mathrm{Pb}$ e $\mathrm{Zn}$ foram superiores às recomendadas pela atual Resolução no. 357/2005 do CONAMA 9. Por sua vez, as concentrações de Cr e Hg estavam dentro dos valores máximos permitidos. A seguir, na Tabela 2, mostram-se as concentrações médias de metais detectadas no estudo realizado em 2000 e as concentrações de metais detectadas no presente estudo (2004) no módulo I do aterro sanitário de Ribeirão Preto.

Ao analisarmos os valores encontrados em ambos os estudos, observa-se que as concentra- 
Figura 2

Variação nas concentrações dos metais no chorume coletado nos tanques de capatação dos módulos I e I|

do aterro sanitário de Ribeirão Preto, São Paulo, Brasil.
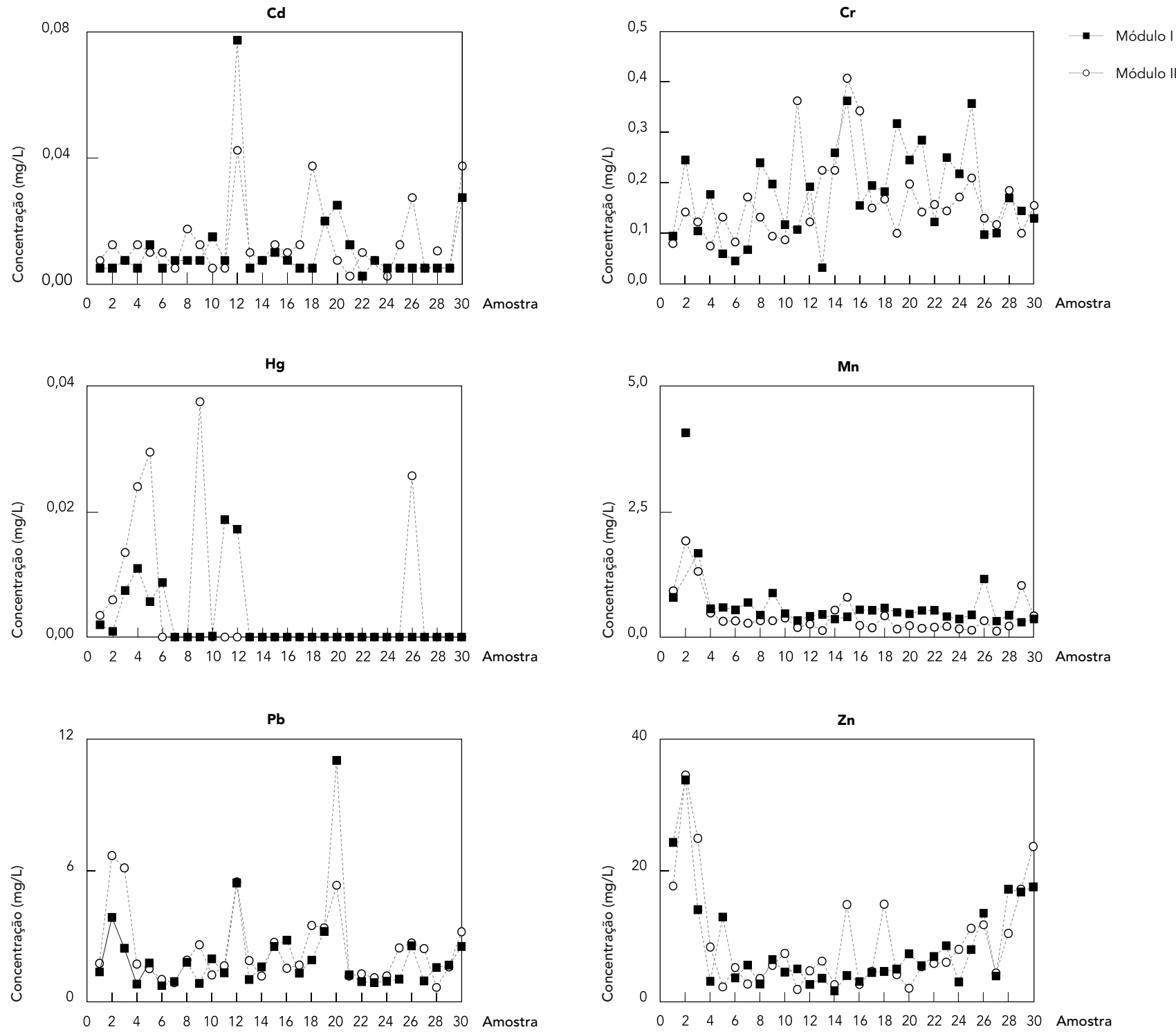

ções dos metais $\mathrm{Cr}, \mathrm{Mn}, \mathrm{Pb}$ e $\mathrm{Zn}$ encontraram-se significativamente maiores nas amostras de chorume do estudo do ano de 2004, o que indica que as concentrações não se atenuaram no período de quatro anos no chorume coletado no tanque de captação do módulo I.

Sabe-se que a matéria orgânica presente no solo do aterro sanitário é capaz de aumentar o potencial de atenuação e de migração de vários metais para esta matriz. Solos contendo alto teor de matéria orgânica tendem a ser ácidos, por causa da formação de ácidos orgânicos por biodegradação, fato que pode reduzir a atenuação de metais. É o caso dos solos da área do aterro sanitário de Ribeirão Preto, o que pode estar retardando a atenuação dos metais no módulo I 17. 
Concentrações dos metais dosados nos anos de 2000 e 2004, no módulo I

do aterro sanitário de Ribeirão Preto, São Paulo, Brasil.

\begin{tabular}{|c|c|c|c|}
\hline Metal dosado & Módulo I (2000) & Módulo I (2004) & Valor de $p$ \\
\hline $\mathrm{Cr}$ & $0,059 \pm 0,0017$ & $0,176 \pm 0,016$ & $<0,001$ \\
\hline $\mathrm{Cd}$ & $0,509 \pm 0,0125$ & $0,010 \pm 0,002$ & $<0,001$ \\
\hline $\mathrm{Mn}$ & $0,030 \pm 0,0010$ & $0,676 \pm 0,128$ & $<0,001$ \\
\hline $\mathrm{Pb}$ & $0,789 \pm 0,0012$ & $2,085 \pm 0,364$ & $<0,001$ \\
\hline $\mathrm{Zn}$ & $0,685 \pm 0,0217$ & $8,429 \pm 1,355$ & $<0,001$ \\
\hline
\end{tabular}

O processo de decomposição dos resíduos sólidos em um aterro sanitário se dá em três fases, que duram cerca de 15 anos, até a estabilização final do processo. A primeira fase ocorre em menos de um mês, sendo responsável por consumir o oxigênio presente no meio e liberar grandes quantidades de dióxido de carbono $\left(\mathrm{CO}_{2}\right)$ e hidrogênio $\left(\mathrm{H}_{2}\right)$. Na segunda fase, microorganismos anaeróbios, também chamados de acetogênicos, hidrolisam e fermentam a celulose e outros materiais putrescíveis, produzindo compostos simples e solúveis, como ácidos voláteis e produtos nitrogenados. Essa fase estende-se até aproximadamente os cinco primeiros anos de vida de um aterro sanitário; o chorume então produzido é altamente biodegradável, apresentando $\mathrm{pH}$ ácido (entre 5,0 e 6,0), e os componentes inorgânicos estão presentes em grandes quantidades. A terceira fase de decomposição é caracterizada pela ação de bactérias metanogênicas e é a fase mais ativa biologicamente. Estabelece-se um equilíbrio dinâmico entre a população de bactérias acetogênicas e metanogênicas, e o chorume produzido na segunda fase de decomposição torna-se fonte de nutrientes para essas bactérias. Nesta fase, ocorre também a produção em grande quantidade de sulfetos, pela redução das mais diversas formas de enxofre, causando a precipitação de cátions inorgânicos, principalmente os metais pesados 18,19 .

Em estudo em dois aterros sanitários na região metropolitana de São Paulo que avaliou a presença de íons de metais pesados $(\mathrm{Pb}, \mathrm{Cu}, \mathrm{Cr}$ e Ni), evidenciou-se a diminuição desses elementos no chorume associado ao aumento do $\mathrm{pH}$, conseqüência das transformações químicas que culminaram na fase metanogênica 20 . No entanto, no presente estudo, não foi evidenciada a atenuação dos níveis de metais no chorume coletado do módulo I do aterro sanitário de Ribeirão Preto, que já se encontrava na fase metanogênica de decomposição na época em que foram coletadas as amostras do líquido, quando comparados com as concentrações de metais nas amostras de chorume provenientes do módulo II, que na época da coleta das amostras tinha apenas três anos de funcionamento. Isso pode estar sugerindo um tempo de estabilização mais demorado do processo de decomposição no módulo I do aterro sanitário de Ribeirão Preto.

Com base nos resultados, considerou-se que concentrações de metais superiores aos limites da resolução do CONAMA poderiam estar acarretando danos ao Sistema de Tratamento de Esgotos por Lodos Ativados, uma vez que o chorume é levado para a Estação de Tratamento de Esgoto de Ribeirão Preto junto com os efluentes captados da rede coletora. Porém, em estudo realizado por Oliveira ${ }^{21}$ na Estação de Tratamento de Esgoto de Ribeirão Preto, no qual, por meio da dosagem das concentrações de metais na entrada e na saída do esgoto, foi avaliada a capacidade de remoção de metais pesados do Sistema de Tratamento por Lodos Ativados, os valores dos metais analisados apresentaram-se abaixo dos limites máximos permitidos pela atual Resolução no. 357/2005 do CONAMA 9, sugerindo que o chorume, quando despejado junto ao esgoto municipal para ser tratado na Estação de Tratamento de Esgoto de Ribeirão Preto, sofre um processo de diluição da concentração de metais, de modo que o funcionamento da estação não seja afetado.

Segundo Serafim et al. ${ }^{22}$, existem algumas possibilidades de tratamento do chorume quando este apresenta níveis elevados de metais, contudo tais alternativas representam um grande desafio, tendo em vista a variação das características desse líquido em face da heterogeneidade dos resíduos dispostos e da idade do aterro sanitário, que determinam a complexidade do chorume, tornando-se difícil a implantação de técnicas efetivas e reprodutíveis de tratamento. 
O monitoramento dos níveis de metais no chorume constitui um importante instrumento de gestão ambiental. Visando à manutenção ou à melhoria da qualidade de vida da população, agências ambientais de todo o mundo passaram a exigir que esse líquido seja mantido em níveis mínimos de produção. A falta de controle e tratamento do chorume gerado em sistemas de disposição de resíduos sólidos promove a contaminação do solo, do ar e das águas superficiais e subterrâneas, além de propiciar a proliferação de vetores de doenças, em detrimento da qualidade do meio ambiente e da saúde pública.

\section{Resumo}

O presente estudo teve como objetivo a avaliação dos níveis de cádmio, chumbo, cobre, cromo, manganês, mercúrio e zinco, no chorume gerado no aterro sanitário de Ribeirão Preto, São Paulo, Brasil. Amostras do líquido foram coletadas nos tanques de captação do módulo I (funcionou de 1989 até outubro do ano de 2000) e do módulo II (vem funcionando desde novembro do ano de 2000), sendo analisadas por Espectrofotometria de Absorção Atômica no setor de metais do Hospital das Clínicas da Faculdade de Medicina de Ribeirão Preto. Os resultados foram comparados com os valores máximos permitidos para concentração de metais em efluentes líquidos presentes na Resolução no. 357/2005 do Conselho Nacional do Meio Ambiente. Foi verificado, também, se existe atenuação na concentração de metais no chorume, considerando a diferença no tempo de vida dos módulos do aterro sanitário em análise. Os resultados deste estudo mostraram que os valores médios de cádmio, cromo, cobre, manganês e mercúrio encontram-se dentro dos limites máximos permitidos, no entanto os valores médios de chumbo e zinco apresentam-se acima dos limites especificados pela referida resolução.

Metais Pesados; Aterros Sanitários; Lixo

\section{Colaboradores}

M. S. Celere participou do planejamento, coleta das amostras, análise laboratorial, interpretação dos resultados e da edição e revisão do manuscrito. A. S. Oliveira colaborou na análise e coleta das amostras. T. M. B. Trevilato assessorou e colaborou na análise das amostras. S. I. Segura-Muñoz concebeu e planejou o estudo junto com M. S. Celere, participando do planejamento, coleta das amostras, análise e interpretação dos resultados, bem como da edição e revisão do manuscrito.

\section{Agradecimentos}

Este estudo foi realizado com o financiamento da Fundação Amparo à Pesquisa do Estado de São Paulo através do auxilio à pesquisa (processo no. 02/11831-6) e da bolsa de iniciação científica (processo no. 03/11589-3). Agradecemos, também, ao Departamento de Água e Esgoto de Ribeirão Preto (DAERP) pela permissão para a coleta das amostras de chorume no aterro sanitário de Ribeirão Preto. 


\section{Referências}

1. Leite CMB, Bernardes RSO, Sebastião A. Método Walkley-Black na determinação da matéria orgânica em solos contaminados por chorume. Revista Brasileira de Engenharia Agrícola e Ambiental 2004; 8:111-5.

2. Instituto Brasileiro de Geografia e Estatística. Pesquisa nacional de saneamento básico: limpeza urbana e coleta de lixo. http://www.ibge.gov.br/ home/estatistica/populacao/condicaodevida/ pnsb/pnsb.pdf (acessado em 06/Abr/2005).

3. Sisino C, Moreira J. Avaliação da contaminação e poluição ambiental na área de influência do aterro controlado do Morro do Céu, Niterói, Brasil. Cad Saúde Pública 1996; 12:515-23.

4. Bertazzoli R, Pelegrini R. Descoloração e degradação de poluentes orgânicos em soluções aquosas através do processo fotoeletroquímico. Química Nova 2002; 25:470-6.

5. Segura-Muñoz SI, Takayanagui AMM, Trevilato TMB, Hering SE. Metais pesados em líquido percolado e água subterrânea da área do aterro sanitário e incinerador de resíduos sólidos de Ribeirão Preto, São Paulo, Brasil. In: Anais de Trabalhos Completos do I Fórum das Universidades Públicas Paulistas Ciência e Tecnologia em Resíduos. v. 1. São Paulo: Legis Summa; 2003; p. 937-48.

6. Mundo do Químico. Metais pesados e seus efeitos. http://www.mundodoquimico.hpg.ig.com.br/metais_pesados_e_seus_efeitos.htm (acessado em 04/Out/2005)

7. Vazoller RF. Microbiologia de lodos ativados. São Paulo: Companhia de Tecnologia de Saneamento Ambiental; 1989.

8. Departamento de Água e Esgoto de Ribeirão Preto. O DAERP. http://cohabrp.com.br/daerp/ i04principal.asp?pagina=/daerp/I04institucional . htm (acessado em 05/Abr/2005).

9. Brasil. Resolução no. 357. Dispõe sobre a classificação dos corpos de água e diretrizes ambientais para o seu enquadramento, bem como estabelece as condições e padrões de lançamento de efluentes, e dá outras providências. Diário Oficial da União 2005; 17 mar.

10. American Public Health Association. Standard methods for the examination of water and wastewater. Washington DC: American Public Health Association; 1998.

11. Varian Australia Pty Ltd. Analytical methods for graphite tube atomizers. Victória: Varian Australia Pty Ltd.; 1988.

12. Oliveira FSJ, Jucá FTJ. Acúmulo de metais pesados e capacidade de impermeabilização do solo imediatamente abaixo de uma célula de um aterro de resíduos sólidos. Eng Sanit Ambient 2004; 9:211-7.
13. Castilhos Jr. AB. Estimativa da distribuição e dos teores dos metais pesados nas diversas frações dos resíduos urbanos no Brasil. Revista Brasileira de Engenharia Agrícola e Ambiental 1988; 1:57-60.

14. Martins I. Manganês. In: Azevedo FA, Chasin AAM, organziadores. Metais: gerenciamento de toxicidade. São Paulo: Editora Atheneu; 2003, p. 265-97.

15. Kuajara O, Sanches JCD, Ballestrin RA, Teixeira EC. Environmental monitoring of the North Porto Alegre landfill, Brazil. Water Environ Res 1997; 69:1170-7.

16. Segura-Muñoz SI. Impacto ambiental na área do aterro sanitário e incinerador de resíduos sólidos de Ribeirão Preto: uma avaliação dos níveis de metais pesados [Tese de Doutorado]. Ribeirão Preto: Escola de Enfermagem de Ribeirão Preto, Universidade de São Paulo; 2002.

17. Maia AD. Avaliação da geração de drenagem ácida em um solo fabricado em laboratório contendo sulfeto de ferro e matéria orgânica [Dissertação de Mestrado]. Rio de Janeiro: Universidade Federal do Rio de Janeiro; 2004.

18. Pacheco JR. Estudo de certas potencialidades de processos oxidativos avançados para o tratamento de percolado de aterro sanitário [Dissertação de Mestrado]. Curitiba: Universidade Federal do Paraná; 2004.

19. Ezaki S, Hypolito R. Comportamento de íons de metais pesados $(\mathrm{Pb}, \mathrm{Cu}, \mathrm{Cr}$ e $\mathrm{Ni})$ no sistema sololixo-chorume de aterros sanitários. In: III Congresso Brasileiro ICTR 2006 Gestão Ambiental e Desenvolvimento Sustentável: Resíduo-Desafio Brasileiro. São Pedro: Instituto de Ciência e Tecnologia em Resíduos e Desenvolvimento Sustentável; 2006. p. 324-7.

20. Ezaki S. Íons de metais pesados ( $\mathrm{Pb}, \mathrm{Cu}, \mathrm{Cr}$ e $\mathrm{Ni})$ associados a solos de cobertura de resíduos sólidos em dois aterros sanitários da região metropolitana de São Paulo-SP [Dissertação de Mestrado]. São Paulo: Instituto de Geociências, Universidade de São Paulo; 2004.

21. Oliveira AS. Tratamento de esgoto pelo sistema de lodos ativados no Município de Ribeirão Preto, SP: avaliação da remoção de metais pesados [Dissertação de Mestrado]. Ribeirão Preto: Escola de Enfermagem de Ribeirão Preto, Universidade de São Paulo; 2006.

22. Serafim AC, Gussakov KC, Silva F, Coneglian CMR, Brito NN, Sobrinho GD, et al. Chorume, impactos ambientais e possibilidades de tratamento. In: III Fórum de Estudos Contábeis. Rio Claro: Centro Superior de Educação Tecnológica; 2003. p. 6-7.

Recebido em 14/Dez/2005

Versão final reapresentada em 23/Ago/2006

Aprovado em 04/Set/2006 